\title{
Novel myocardial markers GADD45G and NDUFS5 identified by RNA-sequencing predicts left ventricular reverse remodeling in advanced non-ischemic heart failure: a retrospective cohort study
}

Togo Iwahana', Sho Okada ${ }^{1 *}$ (D), Masato Kanda', Motohiko Oshima², Atsushi Iwama², Goro Matsumiya ${ }^{3}$ and Yoshio Kobayashi ${ }^{1}$

\begin{abstract}
Background: Left ventricular reverse remodeling (LVRR) has been detected in non-ischemic dilated cardiomyopathy (NIDCM) patients following optimal treatment. However, its prediction with only conventional modalities is often difficult. This study sought to examine whether RNA sequencing (RNA-seq) of myocardium tissue samples could predict LVRR in NIDCM.

Methods: A total of 17 advanced NIDCM patients with left ventricular ejection fraction (LVEF) below 30\% who underwent cardiac biopsy from Left ventricle (LV) were prospectively recruited. They received optimal treatment and followed with echocardiogram every 6 months. Based on LVRR status after 12 months of treatment, patients were divided into the reverse remodeling (RR) or non-RR group. Tissue samples were analyzed by RNA-seq, and a functional analysis of differentially expressed genes was carried out.

Results: There were eight and nine patients in the RR and non-RR groups, respectively. No difference was found in age, sex, disease duration, LV end-diastolic diameter, and LVEF between the two groups. There were 155 genes that were differentially expressed between the two groups. Nicotinamide adenine dinucleotide ubiquinone oxidoreductase subunit (NDUF)S5 and Growth arrest and DNA-damage-inducible protein (GADD)45G, along with several genes related to the mitochondrial respiratory chain and ribosome, were significantly downregulated in the RR as compared to the non-RR group.
\end{abstract}

Conclusion: GADD45G and NDUFS5 are potential biomarkers for LVRR in patients with advanced NIDCM.

Keywords: NIDCM, LVRR, RNA-seq, NDUFS5, GADD45G

\footnotetext{
* Correspondence: shookada-circ@umin.ac.jp

'Department of Cardiovascular Medicine, Chiba University Graduate School

of Medicine, 1-8-1 Inohana, Chuo-ku, Chiba 260-8670, Japan

Full list of author information is available at the end of the article
}

(c) The Author(s). 2020 Open Access This article is licensed under a Creative Commons Attribution 4.0 International License, which permits use, sharing, adaptation, distribution and reproduction in any medium or format, as long as you give appropriate credit to the original author(s) and the source, provide a link to the Creative Commons licence, and indicate if changes were made. The images or other third party material in this article are included in the article's Creative Commons licence, unless indicated otherwise in a credit line to the material. If material is not included in the article's Creative Commons licence and your intended use is not permitted by statutory regulation or exceeds the permitted use, you will need to obtain permission directly from the copyright holder. To view a copy of this licence, visit http://creativecommons.org/licenses/by/4.0/. The Creative Commons Public Domain Dedication waiver (http://creativecommons.org/publicdomain/zero/1.0/) applies to the data made available in this article, unless otherwise stated in a credit line to the data. 


\section{Background}

Heart failure has a complex etiology and is associated with various conditions, and is a major cause of adult mortality. In particular, non-ischemic dilated cardiomyopathy (NIDCM) - which is characterized by left ventricular (LV) dilation and a severely reduced LV ejection fraction (LVEF) without coronary artery disease-is often refractory to established drugs such as $\beta$-blockers, angiotensin-converting enzyme inhibitors, and angiotensin II receptor blockers and to cardiac resynchronization therapy (CRT). Therefore, NIDCM often requires heart transplantation or ventricular assist device (VAD) implantation. However, the former is available only to a limited number of patients, whereas the latter is associated with complications like stroke, bleeding, and infection that can be fatal during the long waiting period for transplantation [1].

On the other hand, many NIDCM patients show recovery of cardiac function after optimal pharmacological or device therapy $[2,3]$. This phenomenon, known as $\mathrm{LV}$ reverse remodeling (LVRR), is associated with improved clinical outcomes. Accordingly, several indices have been identified as predictors of LVRR and heart failure, including blood biomarkers like suppression of tumorigenesis-2 and galectin-3 [4-8], late gadolinium enhancement by cardiac magnetic resonance imaging [9], cardiac fibrosis and cardiomyocyte hypertrophy by histopathological examination $[10,11]$, and washout rate in meta-iodobenzylguanidine myocardial scintigraphy [12]. However, conventional modalities cannot accurately predict the occurrence of LVRR.

Analyzing myocardial gene expression can be more useful for this purpose. Several studies have demonstrated a clear correlation between myocardial expression of certain mRNAs or micro (mi)RNAs and LVRR in NIDCM patients by quantitative reverse transcription PCR [13, 14]. Moreover, RNA sequencing (RNA-seq) and next generation sequencing (NGS) - which enables higher throughput and greater accuracy in the evaluation of gene expression than microarray analysis [15]-is increasingly used in clinical settings [16]. Previous NGS studies have revealed differences in gene expression profiles between ischemic and non-ischemic cardiomyopathy $[17,18]$ or pre- and post VAD support [19-21]. However, there have been no studies using comprehensive transcriptome analysis to examine specific genes related to LVRR. The present study therefore aimed to identify factors that can predict LVRR occurrence by RNA-seq.

\section{Methods}

\section{Patient selection}

Patients with advanced NIDCM whose LVEF was $<30 \%$ by echocardiogram and who underwent cardiac biopsy of the LV at Chiba University Hospital from September 2014 to May 2016 were included in the study. Exclusion criteria were as follows: (i) heart failure with ischemic etiology (defined as past history of myocardial infarction or significant stenosis in the main branches of coronary arteries); (ii) inflammatory or infiltrative heart disease including myocarditis, sarcoidosis, or amyloidosis; (iii) other secondary or metabolic cardiomyopathies such as neuromuscular disease and alcoholic cardiomyopathy; (iv) dependence on hemodialysis; and (v) age younger than 20 years or older than 65 years.

\section{Patient follow-up}

Prior to myocardial biopsy, all patients underwent blood sample collection, echocardiogram, and right heart catheterization. After myocardial biopsy, patients continued to receive optimal treatment including guidelinedirected medical therapy with $\beta$-blockers and reninangiotensin blockers and CRT. Patients were followed for 6 to 12 months, with echocardiogram performed at each follow up; they were then divided into the reverse remodeling $(R R)$ and non-RR groups according to positive or negative LVRR status, respectively. LVRR was defined as (i) LVEF improvement of $>10 \%$ in absolute value, and (ii) LVEF > 30\%.

\section{RNA extraction and CDNA library preparation}

LV myocardium samples were collected at the time of cardiac catheter examination or open heart surgery, including for VAD implantation and valve replacement. Samples were immediately treated with RNAlater RNA stabilization reagent (Qiagen, Valencia, CA, USA) and stored at $-20^{\circ} \mathrm{C}$. Total RNA was extracted using mirVana miRNA Isolation kit (Life Technologies, Carlsbad, CA, USA) according to the manufacturer's instructions, and cDNA libraries were generated using a NEBNext Ultra RNA Library Prep kit (New England BioLabs, Beverly, MA, USA). Sequencing was performed using a HiSeq1500 system (Illumina, San Diego, CA, USA) with a single-read sequencing length of $60 \mathrm{bp}$.

\section{RNA-seq data analysis}

TopHat v.1.3.2 with default parameters was used to map sequences against the UCSC/hg19 reference genome. Gene expression level was quantified using Cufflinks v.2.0.2 [22, 23] as fragments per kilobase of exon per million fragments (FPKM) mapped reads. In the present study, miRNAs and genes expressed at low levels (FPKM $<1$ in all samples) were eliminated. To identify novel biomarkers that predict the occurrence of LVRR, we carried out sensitivity, specificity, and receiver operating characteristic (ROC) curve analyses for each differentially expressed gene (DEG). Functional annotation was performed using the Database for Annotation, Visualization, 
and Integrated Discovery [24-26]. Gene expression profiles of two groups were compared by principal component analysis (PCA). RNA-sequencing data was deposited in the DNA Data Bank of Japan (accession number PRJDB5368).

\section{Quantitative real-time PCR}

When the same cDNAs as for RNA-seq were available, quantitative real-time PCR (qPCR) was performed on a Light Cycler 480 instrument (Roche, Basel, Switzerland) using the Taqman Universal Probe Library and the Light Cycler 480 Probes Master (Roche, Basel, Switzerland) according to the manufacturer's instruction. $18 \mathrm{~S}$ ribosomal RNA was used to normalize the RNA content of the samples. Obtained results were expressed as relative mRNA levels of the cycle threshold value, which was then converted to fold change. Designed primer pairs and probe number are as follows: NDUFS5, $5^{\prime}$-gatttcgtagagtgtttgcttcg-3' (F), 5' -gaggtggaggggtgtactttc-3' (R), probe number \#38 (catalog number 04687965001); GADD45G, 5'-cagccaaagtcttgaacgtg-3' (F), 5'-cctggatcagcgtaaaatgg-3' (R), probe number \#71 (catalog number 04688945001).

\section{Statistical analysis}

For patients' clinical data, continuous variables are expressed as the mean \pm standard deviation and were compared with the unpaired $t$ test, whereas categorical data are expressed as a percentage and were compared with the $X^{2}$ test. $P<0.05$ was considered statistically significant. DEGs were defined as those with a significance $(P)$ value $<0.05$, false discovery rate $<5 \%$, and fold change $>1.5$, which was determined using the $\mathrm{R}$ v.3.1.0 software tag count comparison function [27]. The significance value for functional annotation analysis was $P<0.05$. Data were analyzed using $\mathrm{R}$ version 3.3.2 (The R Foundation, Vienna, Austria).

Logistic regression analysis was used to assess the impact of selected DEGs on LVRR. Odds ratios (OR) and 95\% confidence intervals (CI) were calculated. Confounders with $P$ values $<0.05$ in the univariate analysis were entered into the multivariate model. A $P$ value < 0.05 was regarded as statistically significant. Data were analyzed using STATA version 15.1 (StataCorp, College Station, TX, USA).

\section{Results}

\section{Patient characteristics}

A total of 20 patients were enrolled in this study. Two were excluded due to insufficient RNA amount and heart transplantation in the prior 6 months, respectively. One patient diagnosed with acute fulminant myocarditis was also excluded. Ultimately, 17 patients ( 3 females and 14 males, mean age: $46.6 \pm 11.6$ years) without coronary artery disease or other secondary or specific cardiomyopathies were analyzed. LV myocardial samples were obtained by transcatheter biopsy for four patients, by needle biopsy during aortic valve replacement surgery for three patients, or during VAD implantation for 10 patients.

Patients were divided into RR $(n=8)$ and non-RR $(n=$ 9) groups based on the findings of a follow-up echocardiogram. There were no differences between the two groups in terms of age, sex, disease duration, LVEF on the echocardiogram, brain natriuretic peptide level, cardiac index for right heart catheterization, or ratio of cardioprotective medications (Table 1). On the other hand, proportion of surgical biopsy, inotropes used, and VAD implantation, and serum creatinine concentration were significantly higher in the non-RR than in the RR group (Table 1). Disease duration was more than double in the non-RR group but did not reach statistical significance.

\section{RNA-seq analysis}

A total of 22,416 genes were detected by RNA-seq. After excluding miRNAs and genes with low expression (FPKM $<1$ in each sample), 14,448 genes were retained for analysis. Of these, 155 were differentially expressed between the RR and non-RR groups, with 150 genes upregulated in the non-RR group (Table 2). The top three DEGs were LOC100506295, Nicotinamide adenine dinucleotide ubiquinone oxidoreductase subunit (NDUFS)5, and Growth arrest and DNA-damage-inducible protein (GADD)45G (Fig. 1). Genes encoding other NDUF subunits (NDUFB1, NDUFA1, NDUFS6, NDUFA13, NDUFA3, $N D U F B 7$, and NDUFB3) as well as various ribosomal proteins were also upregulated. ROC curve analysis revealed that the three genes (LOC100506295, NDUFS5, and GADD45G) had high predictive capacity for LVRR (Fig. 2; areas under the curve $=0.99,0.93$, and 0.90 , respectively). A functional enrichment analysis showed significant enrichment of genes related to the mitochondrial respiratory chain or ribosome (Table 3). The PCA showed separate distributions for the RR and non-RR groups (Fig. 3).

\section{qPCR analysis}

qPCR was performed with residual RNA samples. The RR group showed lower expression of NDUFS5 and GADD45G than the non-RR group, consistent with the results obtained by RNA-seq (Fig. 4).

\section{Logistic regression analysis}

Logistic regression analysis was performed to examine the influence of clinical variables including selected DEGs on LVRR (Table 4). In univariate analysis, inotrope use, NDUFS5, and GADD45G showed significant association between LVRR (inotrope use: OR 0.04, 95\% CI $0.003-0.57, P<0.05$; NDUFS5: OR 0.07, 95\% CI 
Table 1 Baseline characteristics of the patients

\begin{tabular}{|c|c|c|c|}
\hline variables & $\begin{array}{l}\text { RR group } \\
(n=8)\end{array}$ & $\begin{array}{l}\text { non-RR group } \\
(n=9)\end{array}$ & $P$ value \\
\hline Age & $46.1 \pm 14.3$ & $47.1 \pm 9.4$ & 0.87 \\
\hline Male Sex, n & 6 & 8 & 0.45 \\
\hline Disease duration (months) & $36.1 \pm 65.5$ & $79.0 \pm 46.5$ & 0.14 \\
\hline Height (cm) & $165 \pm 9$ & $168 \pm 5$ & 0.35 \\
\hline Weight (kg) & $64.1 \pm 12.5$ & $67.2 \pm 9.4$ & 0.56 \\
\hline BMl & $23.4 \pm 3.9$ & $23.8 \pm 3.2$ & 0.83 \\
\hline $\mathrm{HR}(\mathrm{bpm})$ & $90 \pm 23$ & $84 \pm 20$ & 0.63 \\
\hline Method of biopsy (transcatheter /surgery) & $4 / 4$ & 0/9 & 0.019 \\
\hline \multicolumn{4}{|l|}{ Treatment } \\
\hline Beta-blocker, n & 7 & 8 & 0.93 \\
\hline ACEl or ARB, $n$ & 6 & 8 & 0.45 \\
\hline Inotropes, n & 2 & 8 & 0.008 \\
\hline IABP, n & 0 & 2 & 0.16 \\
\hline$A V R, n$ & 2 & 1 & 0.45 \\
\hline VAD implantation, $\mathrm{n}$ & 2 & 8 & 0.008 \\
\hline \multicolumn{4}{|l|}{ Labo data } \\
\hline $\mathrm{Hb}(\mathrm{g} / \mathrm{dL})$ & $12.8 \pm 2.3$ & $11.4 \pm 1.7$ & 0.17 \\
\hline T-Bil (mg/dl) & $1.1 \pm 0.3$ & $1.2 \pm 0.8$ & 0.70 \\
\hline Cre (mg/dl) & $0.92 \pm 0.36$ & $1.40 \pm 0.45$ & 0.029 \\
\hline BNP $(p g / m l)$ & $725 \pm 454$ & $475 \pm 177$ & 0.15 \\
\hline \multicolumn{4}{|l|}{ Echocardiogram } \\
\hline LVDD (mm) & $72 \pm 10$ & $79 \pm 12$ & 0.19 \\
\hline LVDS (mm) & $65 \pm 8$ & $72 \pm 12$ & 0.20 \\
\hline LVEF (\%) & $21.5 \pm 5.1$ & $20.4 \pm 4.2$ & 0.63 \\
\hline LAD (mm) & $50 \pm 9$ & $54 \pm 11$ & 0.43 \\
\hline AR (moderate to severe, $n$ ) & 2 & 1 & 0.45 \\
\hline MR (moderate to severe, $\mathrm{n}$ ) & 6 & 6 & 0.71 \\
\hline TR (moderate to severe, n) & 2 & 3 & 0.71 \\
\hline \multicolumn{4}{|l|}{ Hemodynamics } \\
\hline PAP, mean $(\mathrm{mmHg})$ & $36 \pm 10$ & $38 \pm 10$ & 0.60 \\
\hline PCWP, mean $(\mathrm{mmHg})$ & $27 \pm 6$ & $29 \pm 9$ & 0.57 \\
\hline RAP, mean $(\mathrm{mmHg})$ & $10 \pm 2$ & $13 \pm 6$ & 0.16 \\
\hline $\mathrm{CO}(\mathrm{L} / \mathrm{min})$ & $4.02 \pm 0.68$ & $3.79 \pm 0.90$ & 0.56 \\
\hline $\mathrm{Cl}\left(\mathrm{L} / \mathrm{min} / \mathrm{m}^{2}\right)$ & $2.30 \pm 0.34$ & $2.06 \pm 0.47$ & 0.25 \\
\hline PVR (Wood) & $2.41 \pm 1.66$ & $2.45 \pm 1.61$ & 0.96 \\
\hline
\end{tabular}

Data are shown as the mean value \pm standard deviation, or number of the patients

Abbreviations: $B M I$ body mass index; $H R$ heart rate; $A C E I$ angiotensin converting enzyme inhibitor; $A R B$ angiotensin II receptor blocker; $I A B P$ intraaortic balloon pumping; $A V R$ aortic valve replacement; VAD ventricular assist device; $H b$ hemoglobin; $T$-Bil total bilirubin; Cre creatinine; $L V D D$ left ventricular diastolic diameter; LVDS left ventricular systolic diameter; $L V E F$ left ventricular ejection fraction; $L A D$ left atrial diameter; $A R$ aortic regurgitation; $M R$ mitral regurgitation; TR tricuspid regurgitation; $P A P$ pulmonary artery pressure; $P C W P$ pulmonary capillary wedge pressure; $R A P$ right atrial pressure; $C O$ cardiac output; $C l$ cardiac index; $P V R$ pulmonary vascular resistance

$0.01-0.92, P<0.05$; GADD45G: OR 0.28 , 95\% CI $0.09-$ $0.89, P<0.05)$. In multivariate analysis, neither of these variables showed significant correlation with LVRR, with GADD45G demonstrating borderline significance (OR $0.38,95 \%$ CI $0.13-1.07, P=0.067$ ).

\section{Discussion}

In the present study, we performed RNA-seq of myocardium tissue samples from patients with advanced NIDCM and compared the gene expression profiles of those with and without LVRR. Clinically, patients with 
Table 2 Top 20 differentially expressed genes

\begin{tabular}{|c|c|c|c|c|c|}
\hline Rank & Gene symbol & Official full name & $P$ value & FDR & Fold change \\
\hline 1 & LOC100506295 & & $6.69 \mathrm{E}-07$ & 0.0097 & 1.8320 \\
\hline 2 & NDUFS5 & NADH: ubiquinone oxidoreductase subunit $\mathrm{S} 5$ & $1.51 \mathrm{E}-06$ & 0.0109 & 1.7411 \\
\hline 3 & GADD45G & Growth arrest and DNA damage-inducible gamma & $2.26 \mathrm{E}-06$ & 0.0109 & 2.9929 \\
\hline 4 & PLA2G2A & Phospholipase A2 group IIA & $3.69 \mathrm{E}-06$ & 0.0125 & 10.8842 \\
\hline 5 & RPL27 & Ribosomal protein L27 & $7.84 \mathrm{E}-06$ & 0.0125 & 1.7440 \\
\hline 6 & RPL38 & Ribosomal protein L38 & $9.35 \mathrm{E}-06$ & 0.0125 & 1.8101 \\
\hline 7 & RPS9 & Ribosomal protein $\$ 9$ & 9.37E-06 & 0.0125 & 1.6479 \\
\hline 8 & LOC100506167 & & $9.61 \mathrm{E}-06$ & 0.0125 & 12.2276 \\
\hline 9 & RPL35 & Ribosomal protein L35 & $1.36 \mathrm{E}-05$ & 0.0125 & 1.7464 \\
\hline 10 & C11orfio & Transmembrane protein 258 & $1.50 \mathrm{E}-05$ & 0.0125 & 1.6109 \\
\hline 11 & RPS19 & Ribosomal protein S19 & $1.54 \mathrm{E}-05$ & 0.0125 & 1.6684 \\
\hline 12 & RPS24 & Ribosomal protein S24 & $1.69 \mathrm{E}-05$ & 0.0125 & 1.6003 \\
\hline 13 & RPL31 & Ribosomal protein L31 & $1.71 \mathrm{E}-05$ & 0.0125 & 1.7753 \\
\hline 14 & ATP5EP2 & $\begin{array}{l}\text { ATP synthase, } \mathrm{H}+\text { transporting, mitochondrial F1 complex, } \\
\text { epsilon subunit pseudogene } 2\end{array}$ & 1.83E-05 & 0.0125 & 1.6903 \\
\hline 15 & NDUFB1 & NADH: ubiquinone oxidoreductase subunit B1 & $1.93 \mathrm{E}-05$ & 0.0125 & 1.8706 \\
\hline 16 & CFD & Complement factor D & $2.10 \mathrm{E}-05$ & 0.0125 & 2.7821 \\
\hline 17 & RPS21 & Ribosomal protein S21 & $2.10 \mathrm{E}-05$ & 0.0125 & 1.7684 \\
\hline 18 & OST4 & Oligosaccharyltransferase complex Subunit 4, non-catalytic & $2.14 \mathrm{E}-05$ & 0.0125 & 1.6003 \\
\hline 19 & POLRZL & RNA polymerase II subunit $L$ & $2.37 \mathrm{E}-05$ & 0.0125 & 1.5835 \\
\hline 20 & C14orf2 & Chromosome 14 open reading frame 2 & $2.45 \mathrm{E}-05$ & 0.0125 & 1.7078 \\
\hline
\end{tabular}

FDR false discovery rate

LVRR showed markedly better renal function. They also needed significantly less inotrope support, surgical biopsy and VAD implantation through shorter disease duration than those without LVRR. The major findings were that (i) several genes including LOC100506295, NDUFS5 along with those encoding other NDUF subunits, GADD45G, and some genes encoding ribosomal protein subunits were upregulated in the non-RR as compared to the RR group; and (ii) genes associated with the mitochondrial respiratory chain and ribosome were enriched in the non- $R R$ relative to the $R R$ group.

Other than LOC100506295 whose function is unknown, NDUFS5 was most highly correlated with LVRR. NDUFS5 encodes a subunit of mitochondrial respiratory chain complex I [28]. Previous studies have shown that disturbance of mitochondrial function can cause heart failure [29-31], which is thought to result from increased reactive oxygen species (ROS) production and apoptosis [32]. Decreased complex I activity is also associated with increased ROS production [33-35], which can contribute to the progression of heart failure. Another report demonstrated that AF-HF001, a clinical drug candidate for heart failure, reversed the upregulation of NDUFS5 expression in H9c2 rat cardiomyocytes and attenuated ROS production and myocardial cell apoptosis [36]. These observations suggest that NDUFS5 along with other NDUF subunits of mitochondria complex I play a crucial role in the pathophysiology of heart failure. This is supported by the difference in NDUFS5 expression between the RR and non-RR groups as well as the enrichment of genes related to mitochondrial respiratory chain observed in the present study. Thus, NDUFS5 and mitochondrial complex I subunits may serve as predictive biomarkers for LVRR.

Inborn mitochondrial abnormality, i.e. mitochondrial disease (MD), can involve myocardium and induce cardiac dysfunction through disrupted mitochondrial respiratory chain functions [37]. In addition, even isolated cardiac phenotype is found in MD [38]. Thus, inherent but underdiagnosed MD might be included in the study population. This notion is supported by the previous report that $31 \%$ of MD patients represented cardiac conditions including cardiac dysfunction before the diagnosis [39]. In the present study, we did not examine mutations of mitochondrial DNA nor mitochondria-related nuclear DNA. However, given the lack of typical clinical signs in the participants of our study, MD with manifest cardiomyopathy such as Mitochondrial encephalomyopathy, lactic acidosis, and stroke-like episodes (MELAS), Chronic progressive external ophthalmoplegia (CPEO), and Myoclonic epilepsy with ragged-red fibers (MERRF) are unlikely. 
LOC100506295

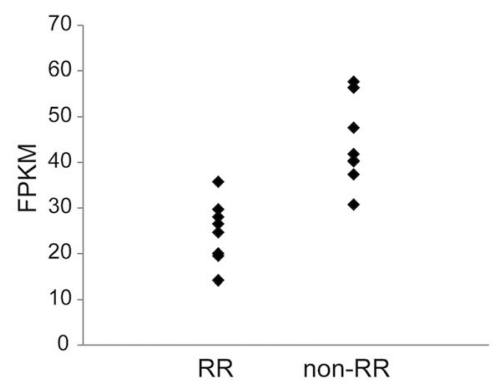

GADD45G

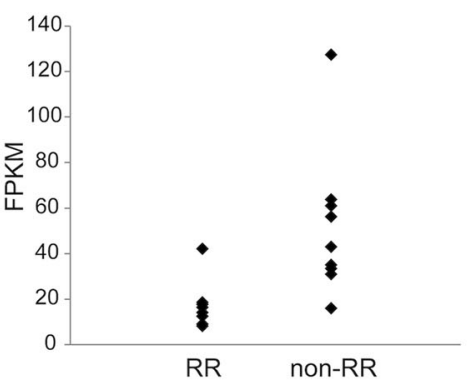

RPL27

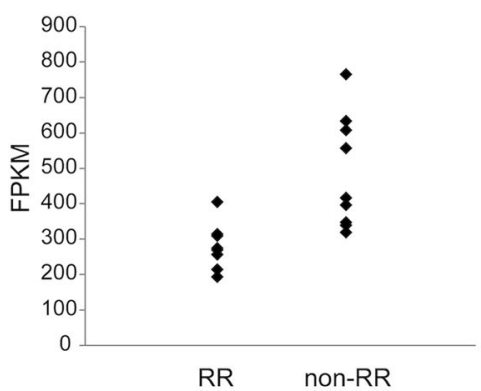

NDUFS5

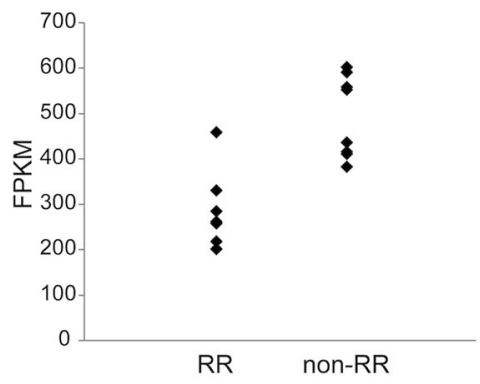

PLA2G2A

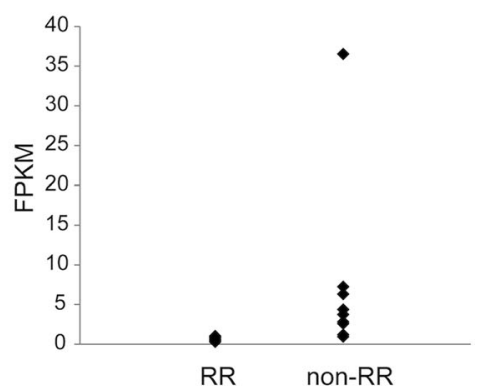

RPL38

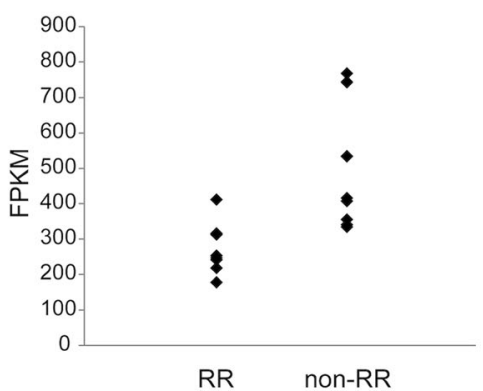

Fig. 1 Scatterplots of the top six genes differentially expressed between RR and non-RR groups. The range of expression is shown as a scatterplot for the top six DEGs ( $n=8$ and 9 in the RR and non-RR groups, respectively). DEG, differentially expressed gene; RR, reverse remodeling; FPKM,

Fragments per kilobase of exon per million fragments mapped reads

Further study is warranted to determine the prevalence of MD in this population.

Apoptosis is another hallmark of mitochondrial function, with mitochondrial permeability transition pore opening to trigger intrinsic apoptosis pathway. Thus, disruption of mitochondrial function can enhance cardiomyocyte apoptosis, leading to progression of heart failure $[40,41]$. In this study, GADD45G was found to be strongly correlated with LVRR. GADD45G is a member of the GADD45 family of proteins that are involved in p38 mitogen-activated protein kinase-dependent cell death [42]. Recent studies have reported that GADD45G overexpression in mice induced cardiomyocyte apoptosis, fibrosis, LV dysfunction, and heart failure, whereas
GADD45G deletion conferred resistance to ischemic injury and cardiomyocyte apoptosis [43]. In our study, GADD45G was more highly expressed in non-RR as compared to RR patients, suggesting that GADD45G upregulation is linked to induction of apoptosis and consequently, a reduced probability of LVRR.

Our study had two novel findings as compared to previous transcriptomic analyses of LVRR. First, we identified markers for predicting LVRR by comprehensive transcriptome analysis of single samples obtained prior to treatment. Some studies showed associations between certain mRNAs or miRNAs and myocardial recovery or subsequent VAD removal after LVAD implantation [13, 14, 44]. However, these studies analyzed only limited number of 

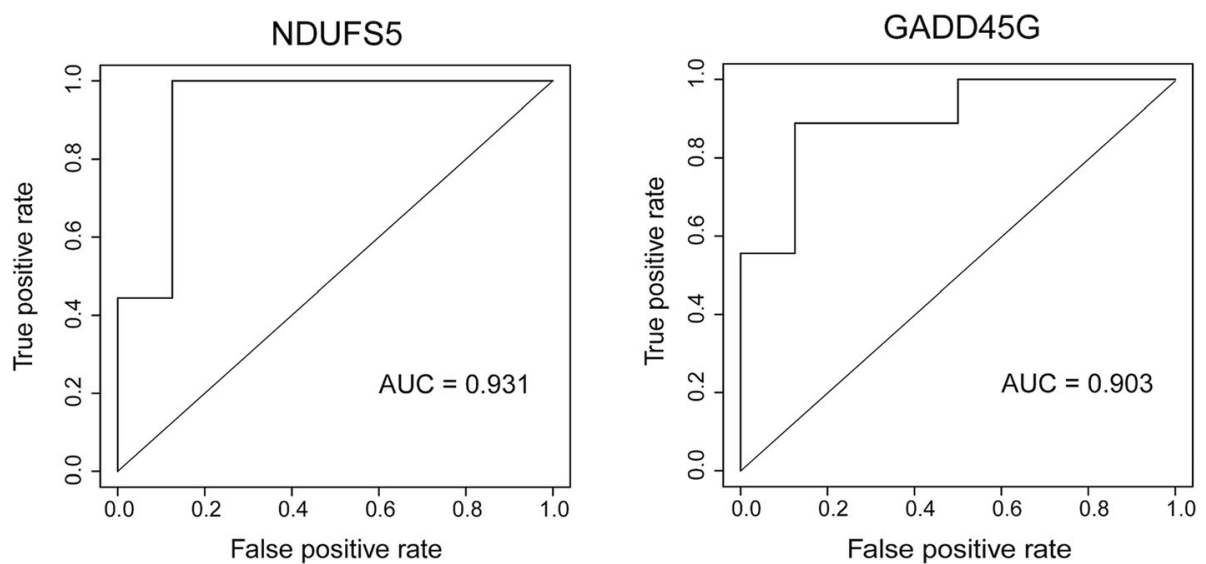

Fig. 2 ROC curve analysis to predict LVRR. Both NDUFS5 and GADD45G showed high predictive capacity for LVRR $(n=8$ and 9 in the RR and nonRR groups, respectively). ROC, receiver operating characteristic; AUC, area under the curve; LVRR, LV reverse remodeling

cardiac gene expression. Dhar et al. performed RNA-seq for the cardiac samples obtained from the patients with non-ischemic advanced heart failure requiring LVAD implantation, and showed that the expressions of myosin light chain kinase and interleukin-6 genes were significantly higher in the LVAD responders as compared to the non-responders. In this study, however, only 95 genes associated with heart failure were examined [44]. RNAseq in the present study performed a comprehensive transcriptome analysis, thereby demonstrating previously unknown, novel mechanisms of LVRR.

Secondly, cardiac biopsy can reveal not only histological abnormalities but also the potential reversibility of cardiac function, which increases its clinical utility for NIDCM. Cardiac biopsy-particularly by the transcatheter method-is associated with risks such as perforation or idiopathic valvular regurgitation, which has thus far limited the diagnostic yield. However, taking into

Table 3 Functional enrichment analysis results

\begin{tabular}{|c|c|c|c|}
\hline Term & P-Value & Fold Enrichment & FDR \\
\hline GO:0006614 SRP-dependent cotranslational protein targeting to membrane & 5.13E-91 & 50.93 & $7.89 \mathrm{E}-88$ \\
\hline GO:0019083 viral transcription & $1.22 \mathrm{E}-84$ & 42.89 & 1.87E-81 \\
\hline GO:0000184 nuclear-transcribed mRNA catabolic process, nonsense-mediated decay & 1.47E-82 & 40.41 & 2.26E-79 \\
\hline GO:0006413 translational initiation & $6.55 \mathrm{E}-78$ & 35.18 & 1.01E-74 \\
\hline GO:0003735 structural constituent of ribosome & $8.01 \mathrm{E}-78$ & 24.63 & 1.03E-74 \\
\hline GO:0006412 translation & $2.00 \mathrm{E}-72$ & 21.82 & $3.08 \mathrm{E}-69$ \\
\hline GO:0005840 ribosome & $4.28 \mathrm{E}-72$ & 29.64 & $5.41 \mathrm{E}-69$ \\
\hline GO:0006364 rRNA processing & $2.87 \mathrm{E}-64$ & 22.53 & 4.42E-61 \\
\hline GO:0022625 cytosolic large ribosomal subunit & $1.80 \mathrm{E}-45$ & 40.55 & 2.27E-42 \\
\hline GO:0022627 cytosolic small ribosomal subunit & $2.08 \mathrm{E}-38$ & 47.97 & $2.62 \mathrm{E}-35$ \\
\hline GO:0005743 mitochondrial inner membrane & $1.61 \mathrm{E}-33$ & 9.47 & 2.04E-30 \\
\hline GO:0044822 poly(A) RNA binding & $1.81 \mathrm{E}-24$ & 4.46 & $2.34 \mathrm{E}-21$ \\
\hline GO:0005747 mitochondrial respiratory chain complex I & $9.49 \mathrm{E}-23$ & 32.38 & 1.20E-19 \\
\hline GO:0015935 small ribosomal subunit & $1.30 \mathrm{E}-22$ & 49.48 & 1.64E-19 \\
\hline GO:0006120 mitochondrial electron transport, NADH to ubiquinone & 1.39E-22 & 31.60 & 2.14E-19 \\
\hline GO:0008137 NADH dehydrogenase (ubiquinone) activity & $6.19 \mathrm{E}-21$ & 29.99 & 7.99E-18 \\
\hline GO:0032981 mitochondrial respiratory chain complex I assembly & 2.67E-20 & 24.58 & 4.10E-17 \\
\hline GO:0005829 cytosol & 4.67E-20 & 2.46 & $5.90 \mathrm{E}-17$ \\
\hline GO:0070062 extracellular exosome & 1.55E-19 & 2.65 & 1.96E-16 \\
\hline GO:0003723 RNA binding & 2.70E-15 & 5.11 & 3.44E-12 \\
\hline
\end{tabular}




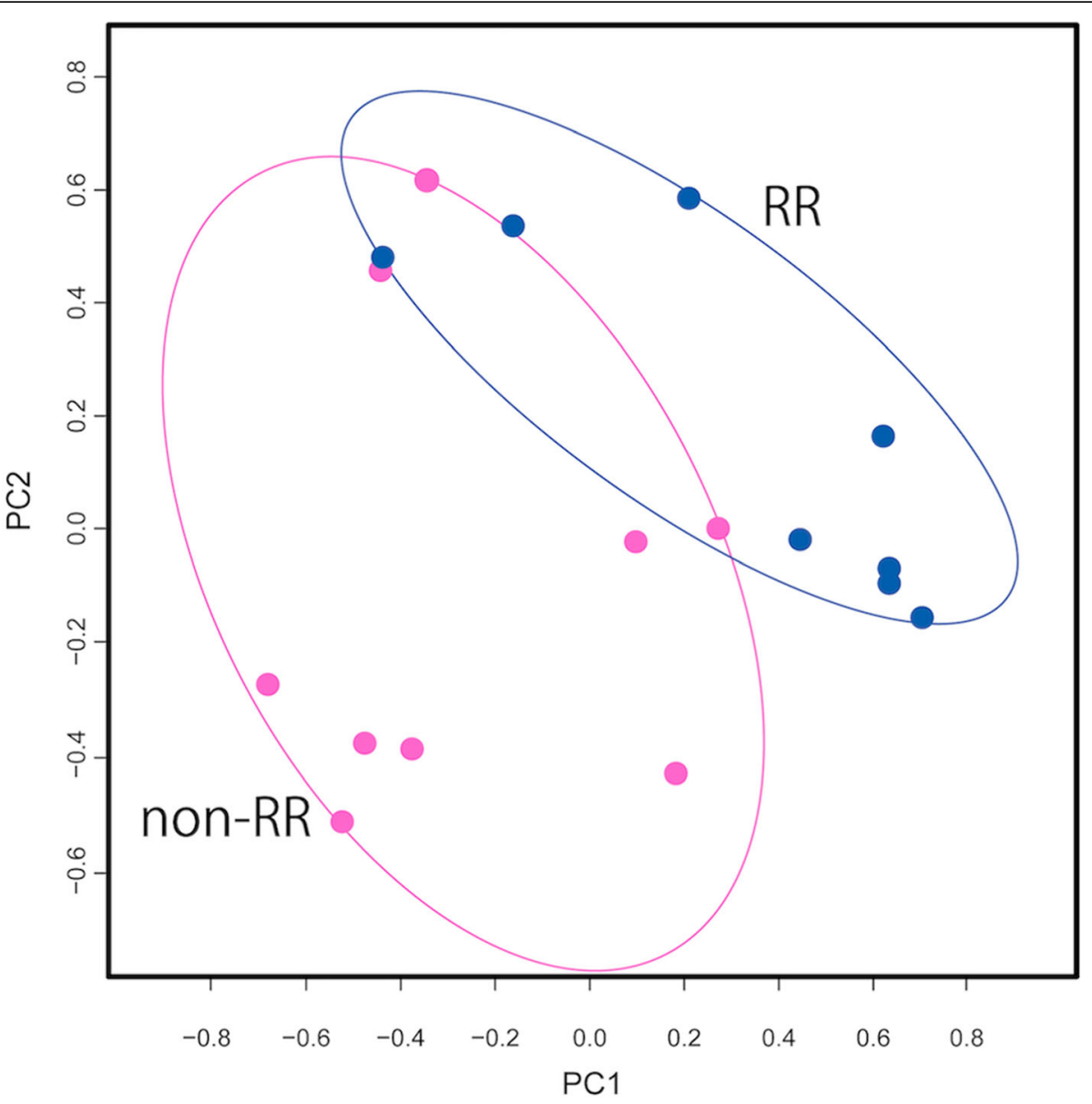

Fig. 3 PCA of distributions in RR and non-RR groups. Distributions differed between RR and non-RR groups ( $n=8$ and 9 in the RR and non-RR groups, respectively). RR, reverse remodeling

a

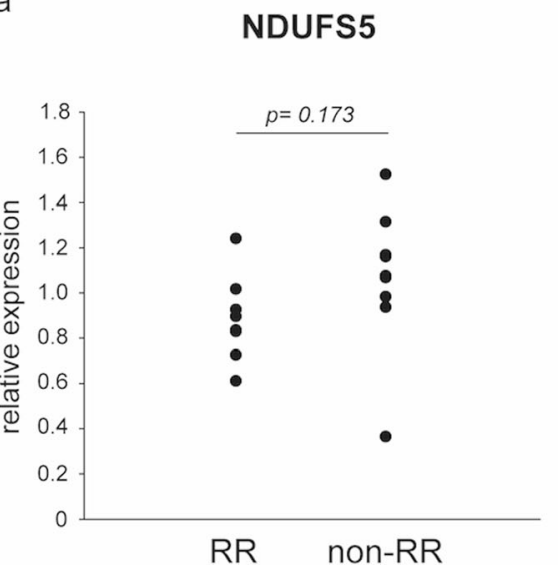

b

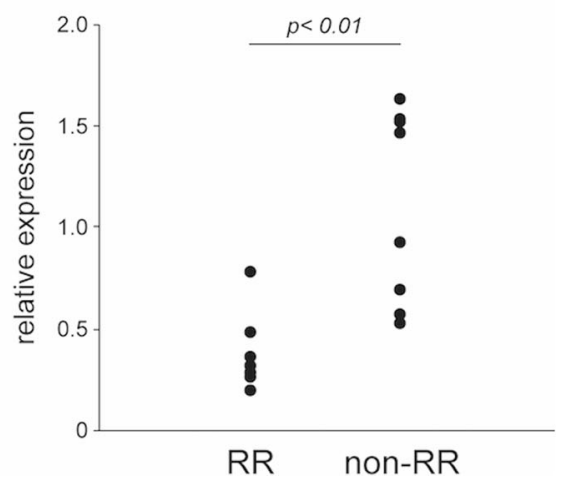

Fig. 4 Relative fold expression levels of NDUFS5 and GADD45G, as determined by quantitative real-time PCR. Gene expression was compared between the RR and non-RR groups; results were consistent with those obtained by RNA-seq. a) NDUFS5 ( $n=8$ and 9 in the RR and non-RR groups, respectively), b) GADD45G ( $n=8$ each) 
Table 4 Odds ratios $(95 \% \mathrm{Cl})$ for the association with left ventricular reverse remodeling

\begin{tabular}{|c|c|c|c|}
\hline \multirow[t]{2}{*}{ Variables } & \multirow[t]{2}{*}{ Univariate } & \multicolumn{2}{|l|}{ Multivariate $^{a}$} \\
\hline & & model 1 & model 2 \\
\hline Age & $0.99(0.91-1.08)$ & & \\
\hline Male Sex & $0.38(0.27-5.17)$ & & \\
\hline Disease duration (months) & $0.98(0.96-1.01)$ & & \\
\hline Height (cm) & $0.94(0.81-1.09)$ & & \\
\hline Weight (kg) & $0.97(0.88-1.07)$ & & \\
\hline HR (bpm) & $1.01(0.97-1.06)$ & & \\
\hline Beta-blocker & $0.88(0.05-16.74)$ & & \\
\hline ACEI or ARB & $0.38(0.03-5.17)$ & & \\
\hline Inotropes & $0.04(0.003-0.57)^{*}$ & $0.002(0.001-18.0)$ & $0.06(0.001-2.95)$ \\
\hline $\mathrm{Hb}(\mathrm{g} / \mathrm{dL})$ & $1.44(0.86-2.41)$ & & \\
\hline Cre $(\mathrm{mg} / \mathrm{dl})$ & $0.05(0.003-1.06)$ & & \\
\hline BNP (pg/ml) & $1.00(0.99-1.01)$ & & \\
\hline LVDD (mm) & $0.94(0.85-1.03)$ & & \\
\hline LVEF (\%) & $1.06(0.85-1.32)$ & & \\
\hline LAD (mm) & $0.96(0.86-1.06)$ & & \\
\hline AR (moderate to severe) & $1.77(0.74-4.23)$ & & \\
\hline MR (moderate to severe) & $0.61(0.20-1.93)$ & & \\
\hline TR (moderate to severe) & $0.70(0.26-1.89)$ & & \\
\hline $\mathrm{PAP}$, mean $(\mathrm{mmHg})$ & $0.97(0.88-1.08)$ & & \\
\hline PCWP, mean $(\mathrm{mmHg})$ & $0.96(0.84-1.10)$ & & \\
\hline RAP, mean (mmHg) & $0.80(0.57-1.12)$ & & \\
\hline $\mathrm{Cl}\left(\mathrm{L} / \mathrm{min} / \mathrm{m}^{2}\right)$ & $4.75(0.35-63.67)$ & & \\
\hline PVR (Wood) & $0.98(0.53-1.83)$ & & \\
\hline NDUFS5 (per 100FPKM) & $0.07(0.01-0.92)^{*}$ & $0.007(0.001-7.24)$ & \\
\hline GADD45G (per 10FPKM) & $0.28(0.09-0.89)^{*}$ & & $0.38(0.13-1.07)$ \\
\hline
\end{tabular}

Abbreviations: $H R$ heart rate; $A C E I$ angiotensin converting enzyme inhibitor; $A R B$ angiotensin II receptor blocker; $H b$ hemoglobin; $C r e$ creatinine; $L V D D$ left ventricular diastolic diameter; $L V E F$ left ventricular ejection fraction; $L A D$ left atrial diameter; $A R$ aortic regurgitation; $M R$ mitral regurgitation; $T R$ tricuspid regurgitation; PAP pulmonary artery pressure; $P C W P$ pulmonary capillary wedge pressure; $R A P$ right atrial pressure; $C I$ cardiac index; $P V R$ pulmonary vascular resistance

${ }^{a}$ Confounders with $p$ values $<0.05$ in each analysis group were included into the model

${ }^{*} p<0.05$

consideration information on the reversibility of cardiac function in NIDCM can facilitate clinical decisionmaking based on biopsy samples. Favorable expressions of the specific genes possibly make us advance aggressive medical treatment to avoid VAD implantation, or even to introduce VAD as a bridge to recovery strategy. By contrast, unfavorable expressions would lead us to prompt introduction of VAD as a bridge to transplant strategy.

The present study had several limitations. First, this study was carried out at a single institution with a small number of samples. Previous studies examining myocardial samples from severely failing hearts could collect only around 10 samples for each treatment group [14, $20,44]$. These facts probably reflect the small population of patients whose heart failure status are severe enough to assess pathological specimen of the heart. Multicenter study will overcome both the possible bias from the single-centered study and the less-powered and nonvalidated results due to small sample size. Second, the issue of small sample size also influenced the results of logistic regression analyses. The model was not established with more than three independent variables due to small number of samples. Even with the challenge, GADD45G demonstrated almost significant predictive value for LVRR in the multivariate model, which highlights the strong contribution of the gene. Reconfirmation of the results with more large samples is needed to show clinically definite significance of NDUFS5 and GADD45G. Third, there were unequal number of females and males. Some transcripts might be expressed in a gender specific manner and serve as a bias for the 
results of the present study. Large-scale and preferably randomized control study is required to resolve this issue. Fourth, adopted treatment strategy differed between the groups. There were more LVAD implantation in the non-RR group, however, this difference was not arbitrary and resulted from the continuing optimal treatment for severe heart failure. Mechanical ventricular support is the most potent cardiac unloading therapy and is thus likely to promote LVRR more efficiently. Nonetheless most patients with LVRR implantation fell upon the non-RR group in the present study, underscoring that the non-RR group actually had little chance to recover cardiac function even after maximal heart failure treatment. Of note, gene expression analyses were performed on the samples prior to LVAD implantation and were not influenced by the difference in the treatment strategy. Fifth, we identified LVRR only by echocardiography in both VAD and non-VAD patients, in contrast to previous studies that defined LV recovery as removal of VAD in VAD-patients [14]. In the present study, there were two VAD patients in the RR group (showing elevations in LVEF from 18 to $39 \%$ and from 13 to 37\%) who nonetheless required VAD support. However, since these patients showed at least partial recovery of cardiac function, pump flow was successfully weaned without right heart failure, aortic valve insufficiency, or readmission. Sixth, the patients had variable etiology, which included drug-induced cardiomyopathy or valvular heart disease. In fact, the etiology may not be known in some patients diagnosed as idiopathic DCM; additional studies are needed to address this issue. However, we presumed that the observed changes in gene expression are common to heart failure patients irrespective of etiology and can therefore serve as universal biomarkers. Finally, the sampled sites differed among patients-i.e., the apical and posterolateral walls were sampled by surgical and transcatheter biopsy, respectively-yet all patients showed a general decrease in cardiac function, implying homogeneous pathophysiology throughout the heart.

\section{Conclusions}

In conclusion, we identified novel genes that are correlated with LVRR by RNA-seq in myocardium tissue samples from patients with advanced NIDCM. NDUFS5 and $G A D D 45 G$ are potential biomarkers for predicting whether patients will develop LVRR, which can inform clinical decision making regarding VAD implantation and/or removal. These findings add value to conventional cardiac biopsy and can potentially improve the treatment of heart failure patients.

\section{Abbreviations}

CPEO: Chronic progressive external ophthalmoplegia; CRT: Cardiac resynchronization therapy; DEG: Differentially expressed gene; FPKM: Fragments per kilobase of exon per million fragments;
GADD45g: Growth arrest and DNA-damage-inducible protein 45G; LV: Left ventricle; LVAD: Left ventricular ventricular assist device; LVEF: Ejection fraction; LVRR: Left ventricular reverse remodeling; MELAS: Mitochondrial encephalomyopathy, lactic acidosis, and stroke-like episodes;

MERRF: Myoclonic epilepsy with ragged-red fibers; miRNA: microRNA; NDUFS5: Nicotinamide adenine dinucleotide ubiquinone oxidoreductase subunit S5; NGS: Next generation sequencing; NIDCM: Non-ischemic dilated cardiomyopathy; PCA: Principal component analysis; qPCR: Quantitative realtime polymerase chain reaction; RNA-seq: RNA sequencing; ROC: Receiver operating characteristic; ROS: Reactive oxygen species; RR: Reverse remodeling; VAD: Ventricular assist device

\section{Acknowledgements}

We would like to thank Atsunori Saraya for his technical assistance and Editage (www.editage.jp) for English language editing.

\section{Authors' contributions}

$\mathrm{Tl}$ designed the study concept. $\mathrm{Tl}, \mathrm{SO}, \mathrm{MK}, \mathrm{MO}, \mathrm{Al}$ and GM sampled and analyzed the data. $\mathrm{TI}, \mathrm{SO}, \mathrm{MK}, \mathrm{MO}, \mathrm{Al}$ and $\mathrm{YK}$ performed statistical analysis and interpreted the data. $\mathrm{Tl}, \mathrm{SO}, \mathrm{MK}, \mathrm{MO}, \mathrm{Al}, \mathrm{GM}$ and $\mathrm{YK}$ drafted and revised the manuscript. All authors read and approved the final manuscript.

\section{Funding}

This work was supported by a Japan Society for the Promotion of Science KAKENHI grant (no. JP15K09064). The funding body had no role in the design of the study, collection, analysis, and interpretation of data, and in writing the manuscript.

\section{Availability of data and materials}

The datasets generated and analyzed during the current study are available in the BioProject of the DNA Data Bank of Japan (DDBJ) repository (https://www.ddbj.nig.ac.jp/bioproject/index-e.html), accession ID PRJDB5368.

\section{Ethics approval and consent to participate}

This study was approved by the Ethics Committee of Chiba University and was conducted according to the principles set forth by the Declaration of Helsinki. All participants provided written, informed consent for their participation.

\section{Consent for publication}

Not Applicable.

\section{Competing interests}

$\mathrm{Tl}, \mathrm{SO}, \mathrm{GM}$, and YK have received research grants from Japan Society for the Promotion of Science KAKENHI grant (no. JP15K09064). Al has received consultancy fee from ReproCell Inc. GM received grants from Otsuka Pharmaceutical Co., Ltd. (Tokyo, Japan), DAllCHI SANKYO COMPANY, LIMITED (Tokyo, Japan), Abbott Medical Japan Co., Ltd. (Tokyo, Japan), Terumo Corporation (Tokyo, Japan), Century Medical, Inc. (Tokyo, Japan), and NIPRO CORPORATION (Osaka, Japan). YK received grants from Otsuka Pharmaceutical Co., Ltd. (Tokyo, Japan), Pfizer Inc. (New York, USA), Medtronic Japan Co., Ltd. (Tokyo, Japan), WIN INTERNATIONAL CO.,LTD (Tokyo, Japan), DAIICHI SANKYO COMPANY, LIMITED (Tokyo, Japan), Amgen Astellas BioPharma K.K (Tokyo, Japan), Mebix, Inc. (Tokyo, Japan), Japan Cardiovascular Research Foundation (Osaka, Japan), and EPI Yamanashi Co.,LTD (Kofu, Yamanashi)

\section{Author details}

'Department of Cardiovascular Medicine, Chiba University Graduate School of Medicine, 1-8-1 Inohana, Chuo-ku, Chiba 260-8670, Japan. ${ }^{2}$ Department of Cellular and Molecular Medicine, Chiba University Graduate School of Medicine, Chiba, Japan. ${ }^{3}$ Department of Cardiovascular Surgery, Chiba University Graduate School of Medicine, Chiba, Japan. 
Received: 1 July 2019 Accepted: 21 February 2020 Published online: 05 March 2020

\section{References}

1. Givertz MM, Mann DL. Epidemiology and natural history of recovery of left ventricular function in recent onset dilated cardiomyopathies. Curr Heart Fail Rep. 2013;10(4):321-30

2. Kirklin JK, Naftel DC, Pagani FD, Kormos RL, Stevenson LW, Blume ED, Miller MA, Baldwin JT, Young JB. Sixth INTERMACS annual report: a 10,000-patient database. J Heart Lung Transplant. 2014;33(6):555-64.

3. Mann DL, Barger PM, Burkhoff D. Myocardial recovery and the failing heart: myth, magic, or molecular target? J Am Coll Cardiol. 2012;60(24):2465-72.

4. Merlo M, Pyxaras SA, Pinamonti B, Barbati G, Di Lenarda A, Sinagra G. Prevalence and prognostic significance of left ventricular reverse remodeling in dilated cardiomyopathy receiving tailored medical treatment. J Am Coll Cardiol. 2011;57(13):1468-76.

5. Ahmad T, Fiuzat M, Neely B, Neely ML, Pencina MJ, Kraus WE, Zannad F, Whellan DJ, Donahue MP, Pina IL, et al. Biomarkers of myocardial stress and fibrosis as predictors of mode of death in patients with chronic heart failure JACC Heart Fail. 2014;2(3):260-8.

6. Bayes-Genis A, de Antonio M, Vila J, Penafiel J, Galan A, Barallat J, Zamora E, Urrutia A, Lupon J. Head-to-head comparison of 2 myocardial fibrosis biomarkers for long-term heart failure risk stratification: ST2 versus galectin3. J Am Coll Cardiol. 2014;63(2):158-66.

7. Felker GM, Fiuzat M, Shaw LK, Clare R, Whellan DJ, Bettari L, Shirolkar SC, Donahue M, Kitzman DW, Zannad F, et al. Galectin-3 in ambulatory patients with heart failure: results from the HF-ACTION study. Circ Heart Fail. 2012; 5(1):72-8.

8. Lok DJ, Lok SI, de la Porte PW B-A, Badings E, Lipsic E, van Wijngaarden J, de Boer RA, van Veldhuisen DJ, van der Meer P. Galectin-3 is an independent marker for ventricular remodeling and mortality in patients with chronic heart failure. Clin Res Cardiol. 2013;102(2):103-10.

9. Kubanek M, Sramko M, Maluskova J, Kautznerova D, Weichet J, Lupinek P, Vrbska J, Malek I, Kautzner J. Novel predictors of left ventricular reverse remodeling in individuals with recent-onset dilated cardiomyopathy. J Am Coll Cardiol. 2013;61(1):54-63.

10. Saito S, Matsumiya G, Sakaguchi T, Miyagawa S, Yamauchi T, Kuratani T, Sawa Y. Cardiac fibrosis and cellular hypertrophy decrease the degree of reverse remodeling and improvement in cardiac function during left ventricular assist. J Heart Lung Transplant. 2010;29(6):672-9.

11. Segura AM, Frazier OH, Demirozu Z, Buja LM. Histopathologic correlates of myocardial improvement in patients supported by a left ventricular assist device. Cardiovasc Pathol. 2011;20(3):139-45.

12. Momose M, Okayama D, Nagamatsu H, Kondo C, Hagiwara N, Sakai S. Longterm prognostic stratification by a combination of (123)Imetaiodobenzylguanidine scintigraphy and ejection fraction in dilated cardiomyopathy. Ann Nucl Med. 2011;25(6):419-24.

13. Felkin LE, Lara-Pezzi EA, Hall JL, Birks EJ, Barton PJ. Reverse remodelling and recovery from heart failure are associated with complex patterns of gene expression. J Cardiovasc Transl Res. 2011;4(3):321-31.

14. Ramani R, Vela D, Segura A, McNamara D, Lemster B, Samarendra V, Kormos $\mathrm{R}$, Toyoda Y, Bermudez C, Frazier OH, et al. A micro-ribonucleic acid signature associated with recovery from assist device support in 2 groups of patients with severe heart failure. J Am Coll Cardiol. 2011;58(22):2270-8.

15. Wang Z, Gerstein M, Snyder M. RNA-Seq: a revolutionary tool for transcriptomics. Nat Rev Genet. 2009;10(1):57-63.

16. Mogensen J, van Tintelen JP, Fokstuen S, Elliott P, van Langen IM, Meder B, Richard P, Syrris P, Caforio AL, Adler Y, et al. The current role of nextgeneration DNA sequencing in routine care of patients with hereditary cardiovascular conditions: a viewpoint paper of the European Society of Cardiology working group on myocardial and pericardial diseases and members of the European Society of Human Genetics. Eur Heart J. 2015; 36(22):1367-70.

17. Liu Y, Morley M, Brandimarto J, Hannenhalli S, Hu Y, Ashley EA, Tang WH, Moravec CS, Margulies KB, Cappola TP, et al. RNA-Seq identifies novel myocardial gene expression signatures of heart failure. Genomics. 2015; 105(2):83-9.

18. Li X, Liu CY, Li YS, XU J, Li DG, Li X, Han D. Deep RNA sequencing elucidates microRNA-regulated molecular pathways in ischemic cardiomyopathy and nonischemic cardiomyopathy. Genet Mol Res. 2016;15(2).
19. Blaxall BC, Tschannen-Moran BM, Milano CA, Koch WJ. Differential gene expression and genomic patient stratification following left ventricular assist device support. J Am Coll Cardiol. 2003;41(7):1096-106.

20. Yang KC, Yamada KA, Patel AY, Topkara VK, George I, Cheema FH, Ewald GA Mann DL, Nerbonne JM. Deep RNA sequencing reveals dynamic regulation of myocardial noncoding RNAs in failing human heart and remodeling with mechanical circulatory support. Circ. 2014;129(9):1009-21.

21. Barsanti C, Trivella MG, D'Aurizio R, El Baroudi M, Baumgart M, Groth M, Caruso R, Verde A, Botta L, Cozzi L, et al. Differential regulation of microRNAs in end-stage failing hearts is associated with left ventricular assist device unloading. Biomed Res Int. 2015;2015:592512.

22. Anders S, Huber W. Differential expression analysis for sequence count data. Genome Biol. 2010;11(10):R106.

23. Trapnell C, Roberts A, Goff L, Pertea G, Kim D, Kelley DR, Pimentel H, Salzberg SL, Rinn JL, Pachter L. Differential gene and transcript expression analysis of RNA-seq experiments with TopHat and cufflinks. Nat Protoc. 2012;7(3):562-78.

24. Dennis G Jr, Sherman BT, Hosack DA, Yang J, Gao W, Lane HC, Lempicki RA. DAVID: database for annotation, visualization, and integrated discovery. Genome Biol. 2003;4(5):P3.

25. Huang DW, Sherman BT, Tan Q, Kir J, Liu D, Bryant D, Guo Y, Stephens R, Baseler MW, Lane HC, et al. DAVID Bioinformatics Resources: expanded annotation database and novel algorithms to better extract biology from large gene lists. Nucleic Acids Res. 2007;35(Web Server issue):W169-75.

26. Sherman BT, Huang da W, Tan Q, Guo Y, Bour S, Liu D, Stephens R, Baseler MW, Lane HC, Lempicki RA. DAVID Knowledgebase: a gene-centered database integrating heterogeneous gene annotation resources to facilitate high-throughput gene functional analysis. BMC Bioinformatics. 2007;8:426.

27. Sun J, Nishiyama T, Shimizu K, Kadota K. TCC: an R package for comparing tag count data with robust normalization strategies. BMC Bioinformatics. 2013;14:219.

28. Wirth C, Brandt U, Hunte C, Zickermann V. Structure and function of mitochondrial complex I. Biochim Biophys Acta. 2016;1857(7):902-14.

29. Larsson NG, Wang J, Wilhelmsson H, Oldfors A, Rustin P, Lewandoski M, Barsh GS, Clayton DA. Mitochondrial transcription factor a is necessary for mtDNA maintenance and embryogenesis in mice. Nat Genet. 1998;18(3): 231-6.

30. Hoshino A, Mita Y, Okawa Y, Ariyoshi M, Iwai-Kanai E, Ueyama T, Ikeda K, Ogata T, Matoba S. Cytosolic p53 inhibits Parkin-mediated mitophagy and promotes mitochondrial dysfunction in the mouse heart. Nat Commun. 2013;4:2308.

31. Schilling JD. The mitochondria in diabetic heart failure: from pathogenesis to therapeutic promise. Antioxid Redox Signal. 2015;22(17):1515-26.

32. Aimo A, Borrelli C, Vergaro G, Piepoli MF, Caterina AR, Mirizzi G, Valleggi A Raglianti V, Passino C, Emdin M, et al. Targeting mitochondrial dysfunction in chronic heart failure: current evidence and potential approaches. Curr Pharm Des. 2016;22(31):4807-22.

33. El-Hattab AW, Scaglia F. Mitochondrial cardiomyopathies. Front Cardiovasc Med. 2016;3:25.

34. Goldenthal MJ. Mitochondrial involvement in myocyte death and heart failure. Heart Fail Rev. 2016;21(2):137-55.

35. Martin-Fernandez B, Gredilla R. Mitochondria and oxidative stress in heart aging. Age (Dordr). 2016;38(4):225-38.

36. Wang G, Tang C, Yan G, Feng B. Gene expression profiling of $\mathrm{H} 9 \mathrm{c} 2$ cells subjected to H2O2-induced apoptosis with/without AF-HF001. Biol Pharm Bull. 2016;39(2):207-14

37. Brown DA, Perry JB, Allen ME, Sabbah HN, Stauffer BL, Shaikh SR, Cleland JG, Colucci WS, Butler J, Voors AA, et al. Expert consensus document: mitochondrial function as a therapeutic target in heart failure. Nat Rev Cardiol. 2017;14(4):238-50

38. Quadir A, Pontifex CS, Lee Robertson H, Labos C, Pfeffer G. Systematic review and meta-analysis of cardiac involvement in mitochondrial myopathy. Neurol Genet. 2019;5(4):e339.

39. Florian A, Ludwig A, Stubbe-Drager B, Boentert M, Young P, Waltenberger J, Rosch S, Sechtem U, Yilmaz A. Characteristic cardiac phenotypes are detected by cardiovascular magnetic resonance in patients with different clinical phenotypes and genotypes of mitochondrial myopathy. J Cardiovasc Magn Reson. 2015;17:40.

40. Narula J, Haider N, Virmani R, DiSalvo TG, Kolodgie FD, Hajjar RJ, Schmidt U, Semigran MJ, Dec GW, Khaw BA. Apoptosis in myocytes in end-stage heart failure. N Engl J Med. 1996;335(16):1182-9. 
41. Wencker D, Chandra M, Nguyen K, Miao W, Garantziotis S, Factor SM, Shirani J, Armstrong RC, Kitsis RN. A mechanistic role for cardiac myocyte apoptosis in heart failure. J Clin Invest. 2003;111(10):1497-504.

42. Ju S, Zhu Y, Liu L, Dai S, Li C, Chen E, He Y, Zhang X, Lu B. Gadd45b and Gadd45g are important for anti-tumor immune responses. Eur J Immunol. 2009;39(11):3010-8.

43. Lucas A, Mialet-Perez J, Daviaud D, Parini A, Marber MS, Sicard P. Gadd45gamma regulates cardiomyocyte death and post-myocardial infarction left ventricular remodelling. Cardiovasc Res. 2015;108(2):254-67.

44. Dhar K, Moulton AM, Rome E, Qiu F, Kittrell J, Raichlin E, Zolty R, Um JY, Moulton MJ, Basma H, et al. Targeted myocardial gene expression in failing hearts by RNA sequencing. J Transl Med. 2016;14(1):327.

\section{Publisher's Note}

Springer Nature remains neutral with regard to jurisdictional claims in published maps and institutional affiliations.

Ready to submit your research? Choose BMC and benefit from:

- fast, convenient online submission

- thorough peer review by experienced researchers in your field

- rapid publication on acceptance

- support for research data, including large and complex data types

- gold Open Access which fosters wider collaboration and increased citations

- maximum visibility for your research: over $100 \mathrm{M}$ website views per year

At BMC, research is always in progress.

Learn more biomedcentral.com/submissions 